\title{
S-1 mediates the inhibition of lymph node metastasis in oral cancer cells
}

\author{
HANA SATO $^{1}$, MASASHI HATORI ${ }^{1}$, YURIKO ANDO ${ }^{1}$, YUJI KURIHARA ${ }^{1}$, SAYAKA TAKAYAMA $^{1}$, \\ TATSUO SHIROTA $^{1}$, TETSUHIKO TACHIKAWA ${ }^{2}$ and SATORU SHINTANI ${ }^{1}$ \\ ${ }^{1}$ Department of Oral and Maxillofacial Surgery, School of Dentistry, Showa University, 2-1-1 Kitasenzoku, \\ Ota-ku, Tokyo 145-8515; ${ }^{2}$ Department of Oral Pathology and Diagnosis, School of Dentistry, \\ Showa University, 1-5-8 Hatanodai, Shinagawa-ku, Tokyo 142-8555, Japan
}

Received April 1, 2009; Accepted April 30, 2009

DOI: $10.3892 /$ or_00000492

\begin{abstract}
S-1, an oral fluorouracil antitumor drug, is composed of three agents: tegafur (FT), 5-chloro-2,4dihydroxypyridine (CDHP), and potassium oxonate (Oxo). Approximately $50 \%$ of oral squamous cell carcinomas (OSCC) exhibit cervical lymph node metastasis. The extent of lymph node involvement is a major determinant in both staging and prognosis of the majority of OSCC. The purpose of this study was to examine the effect of S-1 on the metastatic potential of OSCC cells. We used orthotopic green fluorescence protein (GFP) SAS-L1, in BALB/c nu/nu mice. Mice received oral doses of either $5 \%$ hydroxypropylmethylcellulose (HPMC) for control or S-1 $(20 \mathrm{mg} / \mathrm{kg})$ and were autopsied at 2 weeks. We also performed in vitro experiments using concomitant 5-fluorouracil (5-FU) and CDHP as a drug model of S-1 to determine the effect of S-1 on OSCC invasion and metastasis. Although $100 \%$ (11 of 11) of mice not treated with $\mathrm{S}-1$ showed cervical lymph node metastasis, only $54.4 \%$ (6 of 11) of S-1 treated mice demonstrated metastasis. In in vitro experiments, OSCC cells treated with 5-FU and CDHP showed a marked reduction in invasiveness and in adhesion to laminin coated plates. Western blot analysis revealed that treatment with 5-FU and CDHP suppressed expression of integrins $\alpha_{\mathrm{v}}, \alpha_{3}, \alpha_{6}, \beta_{1}$, $\beta_{3}, \beta_{4}, \beta_{5}$, and $\beta_{6}$. These results suggest that $\mathrm{S}-1$ inhibits tumor proliferation and lymph node metastasis in OSCC cells. Moreover, expression of integrin subunits and the integrin signal transduction pathway may be closely related to metastasis suppression.
\end{abstract}

Correspondence to: Dr Masashi Hatori, Department of Oral and Maxillofacial Surgery, School of Dentistry, Showa University, 2-1-1 Kitasenzoku, Ota-ku, Tokyo 145-8515, Japan

E-mail: hatori@dent.showa-u.ac.jp

Key words: lymph node metastasis, carcinoma, squamous cell, focal adhesion kinase, integrins

\section{Introduction}

Oral squamous cell carcinoma (OSCC) is the most common oral cancer. The incidence of cervical lymph node metastasis in OSCC is high at the initial diagnosis, and presence or absence of cervical lymph node metastasis is an important factor for determining clinical stage and prognosis (1). Hence, suppressing lymph node metastasis is likely to improve prognosis and quality of life (QOL).

The oral anticancer drug S-1 has shown reasonable efficacy in the treatment of head and neck cancer (2-4). S-1 is an oral fluoropyrimidine derivative consisting of tegafur (FT) and 2 modulators, 5-chloro-2,4-dihydroxypyrimidine (CDHP) and potassium oxonate (Oxo), at molar ratios of 1:0.4:1. FT is a prodrug of 5-fluorouracil (5-FU), and CDHP is a reversible competitive inhibitor of an enzyme involved in the degradation of 5-FU. The constituents of S-1 therefore ensure that the FT-derivative, 5-FU, remains in the tumor tissues longer and at higher levels, resulting in enhanced anti-tumor effects $(5,6)$. S-1 can be administered as an oral formulation, which permits treatment on an outpatient basis, with consequent improvement in patient QOL. However, the effects of S-1 on OSCC lymph node metastasis and distant organ metastasis remain poorly understood.

We have previously reported that a lymph node metastasis model using green fluorescence protein (GFP) SASL1 cells can provide real-time information on metastasis development in living animals and on the therapeutic effects of S-1 $(7,8)$. In the present study, we examined the effect of S-1 on regional lymph node metastasis using the GFPSAS-L1 lymph node metastasis model. We also performed in vitro experiments to determine the effect of $\mathrm{S}-1$ on OSCC invasion and metastasis.

\section{Materials and methods}

Chemicals. S-1, CDHP, and hydroxypropylmethylcellulose (HPMC) were provided by Taiho Pharmaceutical Co. (Tokyo, Japan). 5-FU was purchased from LKT Laboratories, Inc. (MN, USA).

Cell lines and cell culture. The GFP-SAS-L1 cell line that we previously established as a stable, high level GFP-expressing 
cell line was used in this study; this cell line permits the detection and visualization of metastases when injected orthotopically into the tongue of a nude mouse (8). Cells were maintained in Dulbecco's modified Eagle's medium (DMEM) supplemented with $10 \%$ heat-inactivated fetal bovine serum, $100 \mathrm{units} / \mathrm{ml}$ penicillin, and $100 \mathrm{mg} / \mathrm{ml}$ streptomycin (complete medium). Subconfluent cells were used in all experiments.

Animals. Five-week-old male nude mice (BALB/c-nu/nu) were purchased from Oriental Yeast Co., Ltd. (Tokyo, Japan). The S-1 group and control group consisted of 11 animals each.

Evaluation of lymph node metastasis. To evaluate the therapeutic effect of S-1, we used a GFP-SAS-L1 lymph node metastatic model (8). In both the $\mathrm{S}-1$ group and control group, a tumor cell suspension $\left(1 \times 10^{6}\right.$ cells $/ 0.03 \mathrm{ml}$ of DMEM) was orthotopically injected into the tongue. The technique performed in this in vivo study to evaluate lymph node metastasis was based on the method of Shintani et al (10). In the S-1 group, S-1 (20 mg/kg) was orally administered from day 3 post-injection, 5 times per week for 2 weeks. Control animals underwent the same protocol but received $5 \%$ HPMC rather than S-1. Animals in both groups were autopsied 2 weeks after the injection. All procedures were performed according to Showa University Animal Care and Use Committee Guidelines (permission number of this experiment: 17059).

Invasion assay. The membrane invasion assay was performed in Matrigel-coated invasion chambers (BectonDickinson Labware, Franklin Lakes, NJ), which we described previously (9). Briefly, resuspended GFP-SAS-L1 cells $\left(5 \times 10^{4}\right)$ were treated with $1 \mu \mathrm{g} / \mathrm{ml}$ of $5-\mathrm{FU}$ and $2 \mu \mathrm{g} / \mathrm{ml}$ of CDHP, while control cells received only the vehicle. Control and treated cells were plated in different upper chambers. A fibroblast-conditioned (WI-38) medium was added to the lower chamber as a chemoattractant for GFP-SAS-L1 cells. Cells were treated with different doses of S-1 and invasive capacity was evaluated for each dose. We assessed the following conditions: control (cells treated with vehicle only); treatment with $1 \mu \mathrm{g} / \mathrm{ml}$ of $5-\mathrm{FU}$ and $2 \mu \mathrm{g} / \mathrm{ml}$ of CDHP; treatment with $5 \mu \mathrm{g} / \mathrm{ml}$ of 5-FU and $10 \mu \mathrm{g} / \mathrm{ml}$ of CDHP and treatment with $10 \mu \mathrm{g} / \mathrm{ml}$ of $5-\mathrm{FU}$ and $20 \mu \mathrm{g} / \mathrm{ml}$ of CDHP. Following $22 \mathrm{~h}$ of incubation at $37^{\circ} \mathrm{C}$ in a humidified $5 \% \mathrm{CO}_{2}$ atmosphere, cells in the upper chamber and on the Matrigel were mechanically removed with a cotton swab. Cells adherent to the outer surface of the membrane were fixed with DiffQuik $^{\circledR}$ stain. The invading cells were counted and photographed under a microscope (Olympus, Provis AX-UCDM) at x200 magnification. Five fields were counted per filter in each group, and the experiment was conducted in triplicate.

Cell adhesion assay. Cells were harvested, washed with phosphate-buffered saline (PBS), and resuspended in a serum-free medium with bovine serum albumin $(10 \mathrm{mg} / \mathrm{ml})$. Control cells and cells treated with $1.0 \mu \mathrm{g} / \mathrm{ml}$ of $5-\mathrm{FU}$ and $2.0 \mu \mathrm{g} / \mathrm{ml}$ of CDHP were plated at a density of $1 \times 10^{3}$ cells per well in a 24 -well plates pre-coated with laminin. Cells were incubated at $37^{\circ} \mathrm{C}$ and $5 \% \mathrm{CO}_{2}$ for $24 \mathrm{~h}$. Non-adherent cells were removed by aspiration and adherent cells were
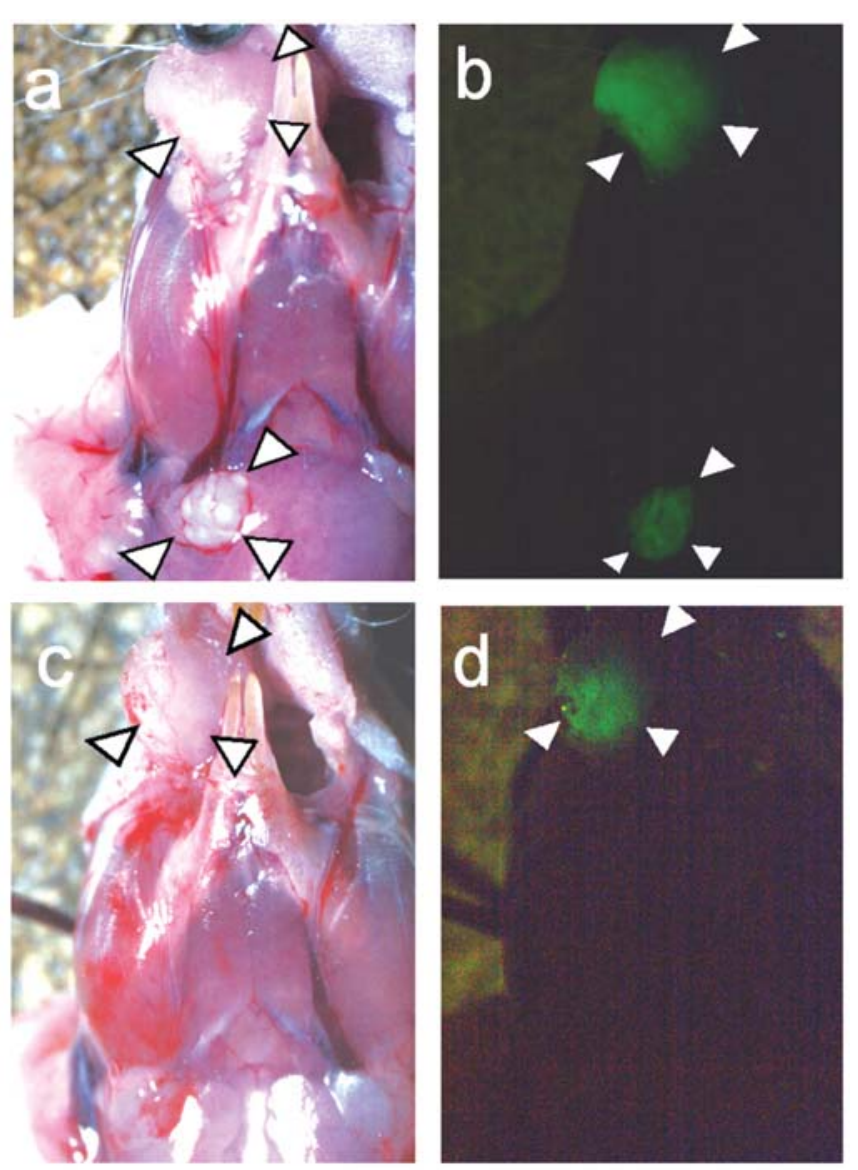

Figure 1. Regional metastasis from orthotopic lingual implantation of GFPSAS-L1 cells. (a and b) A non-treated mouse. An obvious tumor is seen in the tongue. Bilateral metastases are easily indentified within the cervical lymph nodes. (c and d) A mouse that received S-1 (20 mg/kg) orally from day 3 post-injection, 5 times per week for 2 weeks. A tongue tumor is visible, but no metastasis has occurred.

washed 3 times with PBS. Total adherent cells were evaluated by adding $100 \mu 10.04 \%$ crystal violet, incubating at room temperature for $10 \mathrm{~min}$, washing with PBS, and adding $10 \mu 1$ Triton X-100 (ICN Biomedicines, Inc., OH, USA) and $90 \mu 1$ distilled water. The absorbance of each well was determined at $595 \mathrm{~nm}$ in a Microtiter ${ }^{\circledR}$ Plate Reader MRX (DY-NEX, Chantilly, VA). Experiments were conducted in triplicate.

Western blot analysis of integrins. Primary antibodies against integrin $\alpha_{2}, \alpha_{3}, \alpha_{5}, \alpha_{6}, \alpha_{\mathrm{v}}, \beta_{1}, \beta_{3}, \beta_{4}, \beta_{5}, \beta_{6}$, and actin were obtained from Santa Cruz Biotechnology (CA, USA).

Cells were placed in $10 \mathrm{ml}$ of a complete medium containing $5 \times 10^{5}$ cells. After $18 \mathrm{~h}$ of incubation, 5-FU $(1 \mu \mathrm{g} /$ $\mathrm{ml})$ and CDHP $(2 \mu \mathrm{g} / \mathrm{ml})$ were added to the culture. After treatment with 5-FU and CDHP for 12, 24 and $48 \mathrm{~h}$, OSCC cells were lyzed in IGEPAL lysis buffer [20 mM HEPES (pH 7.5), $350 \mathrm{mM} \mathrm{NaCl}, 25 \%$ glycerol, $0.25 \%$ IGEPAL CA630 , and $1 \mathrm{mM}$ sodium o-vanadate] with a complete Mini ${ }^{\circledR}$ protease inhibitor (Roche Diagnostics, Mannheim, Germany). Lysates were centrifuged at $14,000 \mathrm{rpm}$ for $15 \mathrm{~min}$ at $4^{\circ} \mathrm{C}$, and the protein concentration was measured by Bradford assay. Protein $(40 \mu \mathrm{g})$ was separated by SDS-PAGE and transferred to Hybond ${ }^{\mathrm{TM}}$ PVDF membranes (Amersham Pharmacia Biotech, Buckinghamshire, UK); and after blocking by 
Table I. Inhibition of lymph node metastasis of OSCC in the tongue of nude mice.

\begin{tabular}{|c|c|c|c|c|c|c|}
\hline \multirow[b]{3}{*}{ Treatment $^{\mathrm{a}}$} & \multicolumn{3}{|c|}{ Tumor } & \multirow{3}{*}{$\begin{array}{l}\text { Lymph node } \\
\text { Metastasis (\%) }\end{array}$} & \multirow{2}{*}{\multicolumn{2}{|c|}{ Body weight (g) }} \\
\hline & \multirow[b]{2}{*}{ Incidence $^{b}$} & \multicolumn{2}{|c|}{ Tumor volume } & & & \\
\hline & & Average & Range & & Average & Range \\
\hline Control & $11 / 11$ & 71.3 & $55-68$ & 11/11 (100) & 13.6 & $10.2-23$ \\
\hline $\mathrm{S}-1(20 \mathrm{mg} / \mathrm{kg})$ & $11 / 11$ & $23.3^{\mathrm{c}}$ & $49-60$ & $6 / 11(54.5)^{d}$ & 15.3 & $12-18.5$ \\
\hline
\end{tabular}

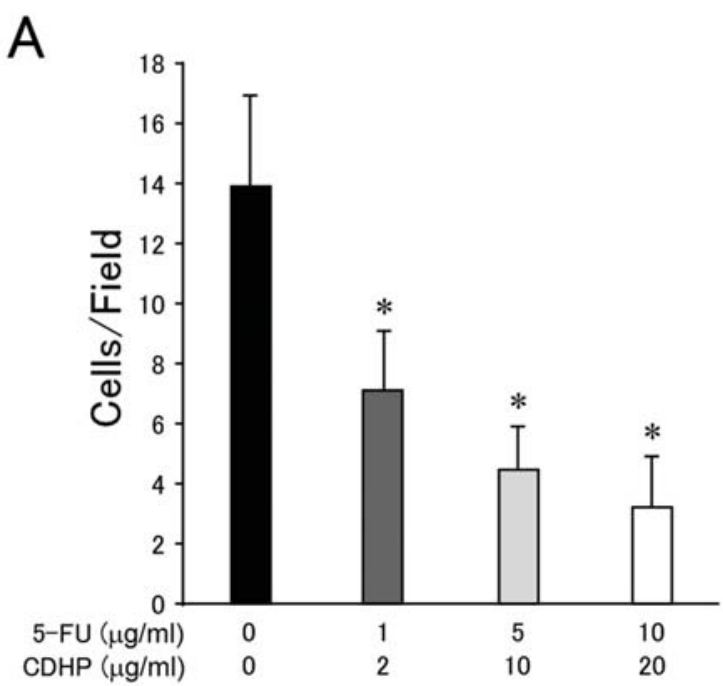

B

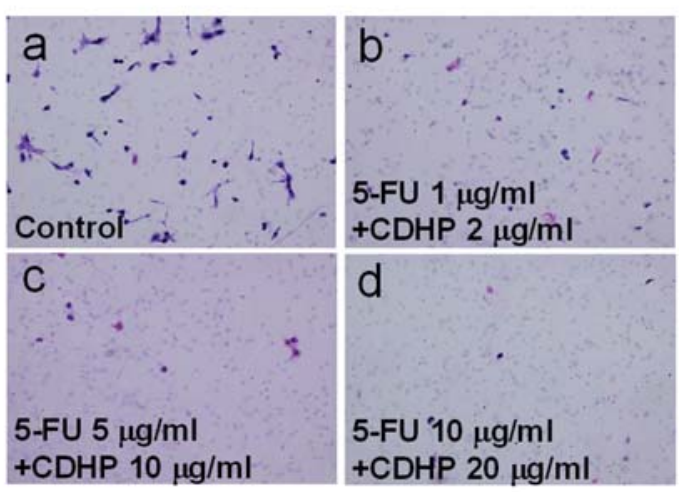

Figure 2. Effects of 5-FU and CDHP on the invasiveness of OSCC cells GFP-SAS-L1 cells were treated with various doses of 5-FU and CDHP Refer to the figure for dosage information. Control cells received vehicle only. Following $22 \mathrm{~h}$ of incubation, invading cells were stained and counted under a microscope at x200 magnification. (A) Five fields were counted per filter in each group. Values are shown as mean \pm standard deviation (SD) of triplicate determinations. ${ }^{*} \mathrm{P}<0.01$ versus control. (B) Cells invading the outer surface of the membrane were stained with Diff-Quik ${ }^{\circledR}$.

incubation for $90 \mathrm{~min}$ in $5 \%$ skim-milk buffer at room temperature, the membranes were treated with each primary antibody followed by the HRP-conjugated secondary antibody. Protein bands were visualized with the ECL ${ }^{\circledR}$
Western blot detection system (Amersham Pharmacia Biotech), according to the manufacturer's instructions.

Western blot analysis of focal adhesion kinase (FAK) and phospho-FAK. Primary antibodies against FAK and phosphor-FAK, were obtained from Santa Cruz Biotechnology. FAK and phosphor-FAK were analyzed using the same method as for the integrins.

Statistical analysis. All calculations were performed using the statistical computer program Statview 5.1 (Avacus, NC). Incidence of metastasis was compared using the unpaired Student's t-test. The significance level was set at $\mathrm{P}<0.05$ for each analysis.

\section{Results}

Effects of $S-1$ on the GFP-SAS-L1 lymph node metastatic model. All mice showed development and significant growth of fluorescent orthotopic tumors. Tongue tumor and lymph node metastasis could be observed in real-time with fluorescence microscopy (Fig. 1). When compared with the control group, the S-1 group experienced reductions in tumor volume and inhibition of metastasis (Table I). Cervical lymph node metastasis was seen in all 11 control mice vs. 6 of $11(54.5 \%)$ $\mathrm{S}-1$ treated mice $(\mathrm{P}<0.05)$. Average tumor volume was significantly reduced from $71.3 \mathrm{~mm}^{3}$ in the control animals to $23.3 \mathrm{~mm}^{3}$ after therapy with $\mathrm{S}-1(\mathrm{P}<0.01)$. Body weight was greater in the S-1 group than in the control group, presumably as a result of a decrease in tumor size leading to greater food intake.

Effects of 5-FU and CDHP on the invasiveness of GFPSAS-L1 cells. To examine the effects of 5-FU and CDHP on the invasiveness of GFP-SAS-L1 cells, we performed the Matrigel invasion assay. As shown in Fig. 2A, cells treated with 5-FU and CDHP showed significantly lower invasiveness than untreated cells $(\mathrm{P}<0.01)$. This occurred in a dose-dependent manner (Fig. 2A). Cells invading the outer surface of the membrane were stained with Diff-Quik ${ }^{\circledR}$ and are shown in Fig. 2B. The number of cells adherent to the outer surface decreased after treatment with 5-FU and CDHP; this also occurred in a dose-dependent manner (Fig. 2B). 


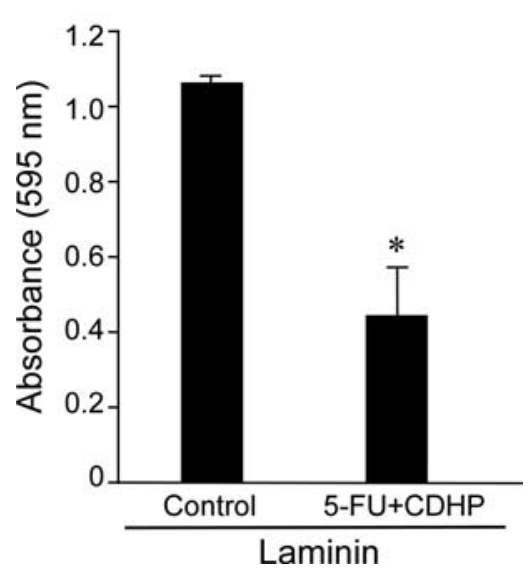

Figure 3. Effects of 5-FU and CDHP on cell adhesion. Adhesion assay to laminin in cells treated with 5-FU $(1.0 \mu \mathrm{g} / \mathrm{ml})$ and CDHP and $(2.0 \mu \mathrm{g} / \mathrm{ml})$ and those that received vehicle only (control). Cell density was measured by protein estimation using BCA reagent. Error bars represent \pm standard error of the mean of triplicate experiments $(\mathrm{P}<0.05)$. OD, optical density.
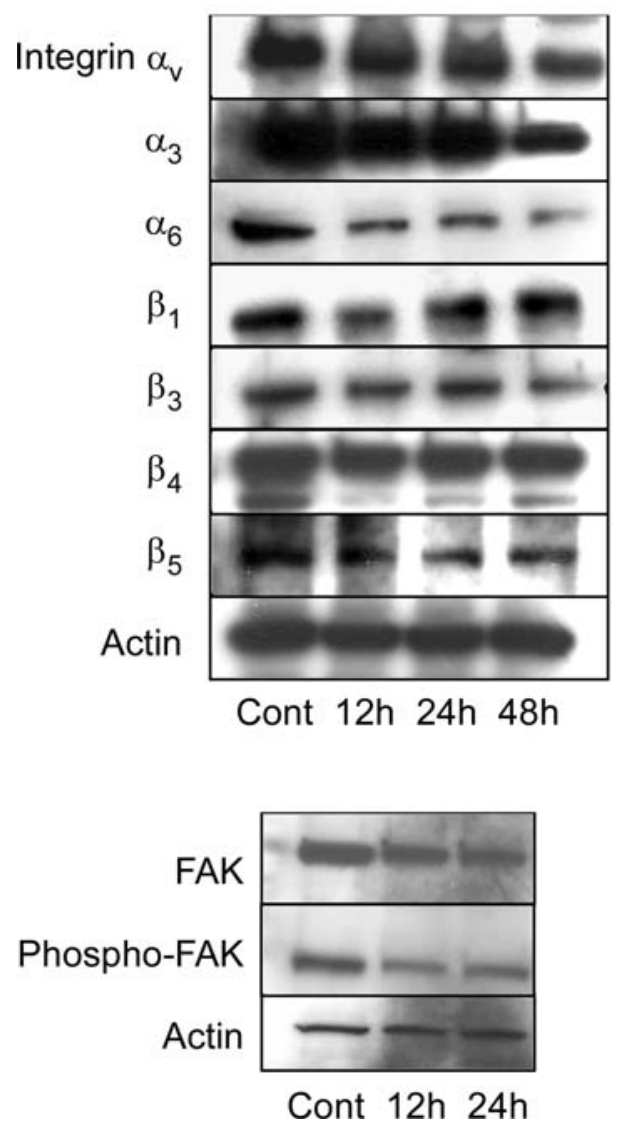

Figure 4. Effects of 5-FU and CDHP on expression of integrins and the FAK signaling pathway. GFP-SAS-L1 cells were treated with 5 -FU $(1.0 \mu \mathrm{g} / \mathrm{ml})$ and CDHP $(2.0 \mu \mathrm{g} / \mathrm{ml})$ or with vehicle only (control). 5-FU and CDHP treatment reduced expression of integrins $\alpha_{3}, \alpha_{6}, \alpha_{v}, \beta_{1}, \beta_{3}$, $\beta_{4}$, and $\beta_{5}$. Phospho-FAK was downregulated in $12 \mathrm{~h}$ by S- 1 treatment.

Effects of 5-FU and CDHP on cell adhesion. Cell adhesion to the extracellular matrix (ECM) is one of the steps involved in invasion and metastasis. The ECM consists of a composite pool of matrix proteins with laminin as its major component. Therefore, we investigated the ability of a stable trans- fectant to adhere to the ECM protein laminin. GFP-SAS-L1 cells treated with 5-FU and CDHP showed a 58.1\% decrease in binding to laminin when compared with control cells $(\mathrm{P}<0.05)$ (Fig. 3).

Effects of 5-FU and CDHP on the expression of integrin subunits. Transmembrane integrins that bind to ECM proteins can generate a signal transduction that regulates cell proliferation and migration events. To examine the effect of 5-FU and CDHP on the expression of integrins and on the FAK pathway, GFP-SAS-L1 cells were treated with 5-FU $(1 \mu \mathrm{g} / \mathrm{ml})$ and CDHP $(2 \mu \mathrm{g} / \mathrm{ml})$. Although 5-FU and CDHP treatment did not significantly affect the expression of integrins $\alpha_{2}, \alpha_{5}$, or $\beta_{6}$, it reduced the expression of integrins $\alpha_{3}, \alpha_{6}, \alpha_{v}, \beta_{1}, \beta_{3}$, $\beta_{4}$, and $\beta_{5}$ (Fig. 4).

Effect of 5-FU and CDHP on FAK phosphorylation. FAK is essential for integrin-stimulated cell migration. Therefore, we evaluated FAK phosphorylation after 5-FU $(1 \mu \mathrm{g} / \mathrm{ml})$ and CDHP $(2 \mu \mathrm{g} / \mathrm{ml})$ treatment. This treatment significantly suppressed FAK phosphorylation in GFP-SAS-L1 cells (Fig. 4).

\section{Discussion}

S-1, a dihydropyrimidine dehydrogenase inhibitory fluoropyrimidine consisting of FT, CDHP, and Oxo in a molar ratio of 1:0.4:1, was developed by Shirasaka et al (6). FT, which is a prodrug of 5-FU, functions as an anticancer agent. Both CDHP and Oxo, which do not exhibit antitumor activity themselves, act as modulators. CDHP competitively inhibits dihydropyrimidine dehydrogenase approximately 180 times more effectively than uracil in vitro (11), leading to the prolonged retention of 5 -FU in the blood $(5,6,12,13)$. Oxo, which competitively inhibits the conversion of 5-FU to 5-fluorouridine 5'-monophosphate by orotate phosphoribosyltransferase, is mainly distributed in the gastrointestinal (GI) tract after oral administration in rats, alleviating the GI toxicity induced by 5 -FU $(6,14)$. In Japan, S-1 is used clinically for the treatment of gastric cancer as well as head and neck tumors.

Cervical lymph node metastasis occurs in approximately $50 \%$ of OSCC. The extent of lymph node involvement is a major determinant in both the staging and prognosis of the majority of OSCC (1). The distribution of lymphatic metastasis can, for the most part, be explained in anatomical and mechanical terms (15). Nonetheless, the underlying cellular mechanisms of lymphatic metastasis remain unclear in OSCC, and no prophylaxis against metastasis to the lymph nodes exists.

In this study, we examined whether $\mathrm{S}-1$ suppresses the ability of OSCC to metastasize. First, we injected GFP-SASL1 into the tongue of nude mice. Three days from injection, when GFP-SAS-L1 had formed a colony in the tongue, S-1 $(20 \mathrm{mg} / \mathrm{kg}$ ) was administered orally. S-1 significantly reduced tumor volume and inhibited lymph node metastasis when compared with control. Body weight was greater in the S-1 group than in the control group, presumably as a result of a decrease in tumor size leading to an increase in food intake. Moreover, GFP-SAS-L1 cells treated with 5-FU and CDHP 
showed significantly lower invasiveness than control cells. Our data confirm that systemic administration of S-1 inhibits metastasis of human OSCC in the tongues of athymic nude mice.

The adhesive interaction between a cell and the ECM mediates cell growth, differentiation, and metabolism, all of which are indispensable in maintaining the organism. Cell adhesion is closely related to the phenomenon of signal transduction as well as to cell structure formation, cell proliferation, and cell differentiation. Integrin, in particular, acts as a representative adhesion receptor in the cell's adhesion to the ECM (16-18). Integrin also controls intracellular information transfer and plays a role in cell differentiation, growth, and migration. FAK is the most prominent of the tyrosine-phosphorylated proteins involved in the cell response to integrin clustering or integrin-mediated adhesion, and it has a major role in signal transduction during focal adhesion (19-22).

To analyze the mechanism of cell adhesion, we conducted an in vitro study using 5-FU and CDHP instead of S-1. We did not use S-1 because S-1 contains FT, which is a prodrug of 5-FU. GFP-SAS-L1 cells treated with 5-FU and CDHP showed reduced adhesion to laminin and downregulation of integrin $\alpha_{3}, \alpha_{6}, \alpha_{\mathrm{v}}, \beta_{1}, \beta_{3}, \beta_{4}$, and FAK. Integrins are transmembrane cell surface receptors composed of noncovalently linked heterodimers of $\alpha$ and $\beta$ chains $(17,23)$. Different integrins generate different signals and some of these integrins may have profound effects on the biologic behavior of tumors. Previous research has found that some integrins such as $\alpha_{1} \beta_{1}, \alpha_{2} \beta_{1}, \alpha_{6} \beta_{1}, \alpha_{6} \beta_{4}, \alpha_{3} \beta_{1}$, and $\alpha_{7} \beta_{1}$ are involved in binding to laminin and that other integrins such as $\alpha_{v} \beta_{6}, \alpha_{5} \beta_{1}$, and $\alpha_{v} \beta_{1}$ contribute to SCC cell migration (24-26). In the present study, downregulation of tumor cell expression of integrins $\alpha_{3}, \alpha_{6}, \alpha_{v}, \beta_{1}, \beta_{3}$, and $\beta_{4}$ after $S$ - 1 therapy appeared to contribute to a reduction in spontaneous metastasis.

The mechanisms by which $\mathrm{S}-1$ regulates FAK and integrins are unclear. The present findings suggest that downregulation of integrins reduced attachment of cells to ECM and thereby diminished metastasis. We also found that tumor cells with downregulated FAK activity became less adherent to the ECM. FAK is associated with integrins within focal adhesions, and integrin activation by an ECM ligand is associated with increased tyrosine phosphorylation and kinase activity of FAK (26).

The activation of FAK plays an important role in the adhesion and spread of integrin-mediated cells. FAK-deficient cells show decreased migration, and FAK overexpression enhances Chinese hamster ovary $(\mathrm{CHO})$ cell migration $(27,28)$. The present finding that tumor cells with downregulated FAK activity also became less adherent to the ECM suggests that S-1 is involved in the regulation of FAK phosphorylation. S-1 may lead to downregulation of the expression of certain integrins (29). The results of the present study confirm that systemic administration of S-1 inhibits metastasis of human OSCC cells grafted in the tongue of athymic nude mice. Hence, the selective downregulation of integrin expression and FAK phosphorylation by S-1 therapy might lead to reduced cell adhesion to the ECM, contributing to a reduction in spontaneous metastasis from these highly metastatic tumors.

\section{Acknowledgements}

We would like to thank Dr Gou Yamamoto and Dr Tomohide Isobe (Department of Oral Pathology and Diagnosis, School of Dentistry, Showa University) for the kind support of this work.

\section{References}

1. Snow GB, van den Brekel MW, Leemans CR and Patel P: Surgical management of cervical lymph nodes in patients with oral and oropharyngeal cancer. Recent Results Cancer Res 134: 43-55, 1994 .

2. Shirasaka T, Tsukuda M, Inuyama $Y$ and Taguchi T: New Oral anticancer drug, TS-1 (S-1)- From bench to clinic. Gan To Kagaku Ryoho 28: 855-864, 2001.

3. Ikeda H, Takebe Y, Irie A, Mizoguchi Y, Yamada K, Shibahara $\mathrm{K}$ and Inokuchi $\mathrm{T}$ : A case report of tongue squamous cell carcinoma showing a complete response to TS-1. Gan To Kagaku Ryoho 30: 677-679, 2003.

4. Koga M, Aoki M, Anegawa E, et al: Clinical evaluation of palliative chemotherapy with $\mathrm{S}-1$ for oral cancer patients. Gan To Kagaku Ryoho 34: 719-723, 2007.

5. Shirasaka T, Nakano K, Takechi T, et al: Antitumor activity of $1 \mathrm{M}$ tegafur-0.4M 5-chloro-2,4-dihydroxypyridine-1M potassium oxonate (S-1) against human colon carcinoma orthotopically implanted into nude rats. Cancer Res 56: 2602-2606, 1996.

6. Shirasaka T, Shimamoto S, Ohshimo H, et al: Development of a novel form of an oral 5-fluorouracil derivative ( $\mathrm{S}-1)$ directed to the potentiation of the tumor selective cytotoxicity of 5-fluorouracil by two biochemical modulators. Anticancer Drugs 7: 548-557, 1996.

7. Aida T, Irie $\mathrm{T}$ and Tetsuhiko $\mathrm{T}$ : Establishment and charactalization of human oral squamous cell carcinoma cell line with highly lymph node metastatic potential. J Jpn Soc Oral Tumors 13: 66-72, 2001

8. Shintani S, Mihara M, Nakahara Y, Aida T, Tachikawa T and Hamakawa H: Lymph node metastasis of oral cancer visualized in live tissue by green fluorescent protein expression. Oral Oncol 38: 664-669, 2002

9. Kinugasa Y, Hatori M, Ito H, Kurihara Y, Ito D and Nagumo M: Inhibition of cyclooxygenase-2 suppresses invasiveness of oral squamous cell carcinoma cell lines via down-regulation of matrix metalloproteinase-2 and CD44. Clin Exp Metastasis 21: 737-745, 2004

10. Shintani S, Li C, Mihara M, Nakashiro K and Hamakawa H: Gefitinib ('Iressa'), an epidermal growth factor receptor tyrosine kinase inhibitor, mediates the inhibition of lymph node metastasis in oral cancer cells. Cancer Lett 201: 149-155, 2003.

11. Tatsumi K, Fukushima M, Shirasaka T and Fujii S: Inhibitory effects of pyrimidine, barbituric acid and pyridine derivatives on 5-fluorouracil degradation in rat liver extracts. Jpn J Cancer Res 78: 748-755, 1987.

12. Takechi T, Nakano K, Uchida J, et al: Antitumor activity and low intestinal toxicity of S-1, a new formulation of oral tegafur, in experimental tumor models in rats. Cancer Chemother Pharmacol 39: 205-211, 1997.

13. Hirata K, Horikoshi N, Aida K, et al: Pharmacokinetic study of S-1, a novel oral fluorouracil antitumor drug. Clin Cancer Res 5: 2000-2005, 1999.

14. Shirasaka T, Shimamoto $Y$ and Fukushima M: Inhibition by oxonic acid of gastrointestinal toxicity of 5-fluorouracil without loss of its antitumor activity in rats. Cancer Res 53: 4004-4009, 1993.

15. Shah JP, Candela FC and Poddar AK: The patterns of cervical lymph node metastases from squamous carcinoma of the oral cavity. Cancer 66: 109-113, 1990.

16. Hynes RO: Integrins: a family of cell surface receptors. Cell 48: 549-554, 1987.

17. Hynes RO: Integrins: versatility, modulation, and signaling in cell adhesion. Cell 69: 11-25, 1992.

18. Schwartz MA, Schaller MD and Ginsberg MH: Integrins: emerging paradigms of signal transduction. Annu Rev Cell Dev Biol 11: 549-599, 1995.

19. Hanks SK, Calab MB, Harper MC and Patel SK: Focal adhesion protein-tyrosine kinase phosphorylated in response to cell attachment to fibronectin. Proc Natl Acad Sci USA 89: 8487-8491, 1992. 
20. Richardson A and Parsons JT: Signal transduction through integrins: a central role for focal adhesion kinase? Bioessays 17: 229-236, 1995

21. Schaller MD, Borgman CA, Cobb BS, Vines RR, Reynolds AB and Parsons JT: pp125FAK, a structurally distinctive proteintyrosine kinase associated with focal adhesions. Proc Nat Acad Sci USA 89: 5192-5196, 1992.

22. Schaller MD and Parsons JT: Focal adhesion kinase and associated proteins. Ourr Opin Cell Biol 6: 705-710, 1994

23. Sonnenberg A: Integrins and their ligands. Curr Top Microbiol Immunol 184: 7-35, 1993.

24. Koivisto L, Grenman R, Heino J and Larjava H: Integrins $\alpha 5 \beta 1, \alpha v \beta 1$, and $\alpha v \beta 6$ collaborate in squamous carcinoma cell spreading and migration on fibronectin. Exp Cell Res 255: $10-17,2000$.

25. Thomas GJ, Lewis MP, Whawell SA, et al: Expression of the avß6 integrin promotes migration and invasion in squamous carcinoma cells. J Invest Dermatol 117: 67-73, 2001.
26. Xue H, Atakilit A, Zhu W, Li X, Ramous DM and Pytela R : Role of the $\alpha \mathrm{V} B 6$ integrin in human oral sqamous cell carcinoma growth in vivo and in vitro. Biochem Biophys Res Commun 288: 610-618, 2001.

27. Cary LA, Chang JF and Guan JL: Stimulation of cell migration by overexpression of focal adhesion kinase and its association with Src and Fyn. J Cell Sci 109: 1787-1794, 1996.

28. Ilic D, Furuta Y, Kanazawa S, et al: Reduced cell motility and enhanced focal adhesion contact formation in cell from FAKdeficient mice. Nature 377: 539-544, 1995.

29. Nagoshi Y, Yamamoto G, Irie T and Tachikawa T: Expression of FAK-related non-kinase (FRANK) coincides with morphological change in the early stage of cell adhesion. Med Mol Morphol 39: 154-160, 2006. 